\section{Original Article}

Neonatal Med 2015 November;22(4):187-191

http://dx.doi.org/10.5385/nm.2015.22.4.187

pISSN 2287-9412 . eISSN 2287-9803 neonatal
medicine

\title{
Adverse Drug Reaction in the Neonatal Intensive Care Unit: A Single Center Study
}

Kyoung-Ah Kwon, M.D., Ha-Su Kim, M.D., Young-Hee Nam, M.D.* , and Myo-Jing Kim, M.D.

Departments of Pediatrics and Internal Medicine*, Dong-A University College of Medicine, Busan, Korea

\section{ABSTRACT}

Purpose: Little research has been conducted on adverse drug reactions in neonates, particularly in Korea, where no studies have been reported.

Methods: We conducted a retrospectively study using medical records in a neonatal intensive care unit from August 1, 2013 to July 31, 2014. The adverse drug reactions were evaluated according to the Naranjo algorithm, World Health OrganizationUppsala Monitoring Centre, and the Korean adverse drug reaction algorithm.

Results: Of the 410 infants hospitalized during the study period, 57 cases of adverse drug reactions were reported in 40 infants (9.8\%). The average gestational age was $28.4 \pm 4.3$ weeks, the average birth weight was $1,184.1 \pm 622.0 \mathrm{~g}$, and the adverse drug reactions were reported at an average of $21.0 \pm 29.7$ days after birth. Causative agents were identified as electrolytes (36.8\%), respiratory medication (14.0\%), total parenteral nutrition (12.3\%), lipid emulsion (10.5\%), antibiotics (7.0\%), non-steroidal antiinflammatory drugs (NSAIDs, $7.0 \%)$, sedatives (7.0\%), vaccine (3.5\%), and an antiviral medication (1.8\%). Of the 57 cases, 55 (96.5\%) cases demonstrated meaningful adverse drug reactions, defined as those given a score of "possible or above" in all 3 adverse drug reaction algorithms.

Conclusion: More emphasis is warranted in the field of neonatal adverse drug reactions.

Key Words: Adverse drug reactions, Newborn

\section{INTRODUCTION}

Adverse drug reactions (ADR) are an unintended and harmful effect resulting from the use of medications intended for diagnostic, therapeutic, or preventative reasons ${ }^{1,2}$. Adverse drug reactions are frequent and expensive causes of mortality and morbidity that appear to be increasing in patients of all ages. Adverse drug reactions in neonates are related to the immature metabolism process, and its prevalence in neonates is estimated to be three times that in adults ${ }^{3-5}$. Adverse drug reactions increase dramatically when more than four different drugs are administered ${ }^{1}$. Among high-risk newborns admitted to
Received: 27 June 2015

Revised: 21 August 2015

Accepted: 24 August 2015

Correspondence to:

Myo-Jing Kim, M.D.

Department of Pediatrics, Dong-A

University College of Medicine, 26

Daesingongwon-ro, Seo-gu, Busan 49201, Korea

Tel: +82-51-240-2589

Fax: +82-51-242-2765

E-mail: myojing@dau.ac.kr

Copyright(c)

By Korean Society of Neonatology.

All right reserved.

This is an Open-Access article distributed under the terms of the Creative Commons Attribution Non-Commercial License (http://creativecommons.org/licenses/ by-nc/3.0), which permits unrestricted non-commercial use, distribution, and reproduction in any medium, provided the original work is properly cited. 
level III neonatal intensive care units (NICU), 15\% have had more than 10 different drugs administered to them and in $30 \%$ of the cases, the infant experiences more than one adverse drug reaction $^{6,7)}$. The metabolism of medications in neonates varies according to the postnatal age and gestational age, because it is related to the transportation of drug substances from the mother to the infant through the placenta or milk and immaturity of the organs. The immaturity of the liver and kidneys affects drug metabolism ${ }^{8,9}$. Thus, it is inappropriate to apply information regarding drug metabolism in adults or children directly to newborns. However, few drugs have been studied with regard to their effects on newborns. In particular, up to $55 \%$ to $80 \%$ of drugs in current use in NICU are unlicensed or off-label drugs due to the lack of clinical data, and $>50 \%$ of all prescriptions are unlicensed or off-label drugs. Approximately $80 \%$ to $97 \%$ of all high-risk newborns admitted to a neonatal intensive care unit are prescribed $>1$ unlicensed or off-label drug $^{10)}$. These problems cause dilemmas for the clinicians responsible for prescribing medication. However, to date, to the best of our knowledge, there is no Korean study that has reported adverse drug reactions occurring in a neonatal intensive care unit.

Thus, the present study was conducted to analyze and report the findings of adverse drug reactions in a single neonatal intensive care unit.

\section{MATERIALS AND METHODS}

\section{Subjects}

The study was retrospectively conducted using medical records of infants admitted to the neonatal intensive care unit in Dong-A University Hospital between August 1, 2013 and July 31, 2014. The subjects were patients who were reported to the regional drug monitoring center by the doctor or nurse in charge of adverse reactions that were most likely related to drugs administered during hospital treatment. The varying symptoms caused by a single drug, as well as single symptoms caused by various drugs, were defined in isolated reports.

\section{Methods}

The analysis of causality between the drug and adverse reaction was jointly conducted by a neonatologist, a pharmacist specializing in adverse drug reactions, and an internist speciali- zing in drug allergies at the regional drug monitoring center. The cases were evaluated according to Naranjo's scale ${ }^{11)}$, the World Health Organization-Uppsala Monitoring Centre (WHOUMC) standard ${ }^{2)}$, and the Korean adverse drug reaction algorithm $^{12)}$. The scores on Naranjo's scale were classified into 4 stages of definite, probable, possible, and doubtful. The stages in the WHO-UMC standard were certain, probable or likely, possible, unlikely, conditional or unclassified, unassessable or unclassifiable. The Korean algorithm had the following 4 stages of classifications: certain, probable, possible, and unlikely.

\section{Statistics}

The data were expressed as the number of patients, cases, and percentages using descriptive statistics. Values are shown as averages \pm standard deviation.

\section{RESULTS}

\section{Characteristics of the study patients}

Of the 410 patients admitted to the neonatal intensive care, 40 patients experienced adverse drug reactions, thereby exhibiting a 9.8\% incidence. The average gestation age of the study subjects was $28.6 \pm 4.3$ weeks, the average birth weight was $1,184 \pm 622 \mathrm{~g}$, and adverse drug reactions occurred at an average of $21 \pm 30$ days after birth. The total number of prescriptions during the study period was 43,641 cases with 57 reported cases of adverse drug reactions, showing an incidence of $0.13 \%$.

\section{Adverse drug reaction symptoms and causative agents}

Magnesium sulfate was the number one causative drug with 21 cases $(36.8 \%)$, and among these, the most frequent cases occurred in which the mothers had been administered the drug $(\mathrm{n}=12$ cases, $21.1 \%)$, the remaining 9 cases were associated with the maintenance dose $(0.5 \mathrm{mEq} / \mathrm{kg})$ in total parenteral nutrition, with all cases showing hypermagnesemia (serum magnesium $>2.8 \mathrm{mg} / \mathrm{dL})$. A total of 8 cases $(14.0 \%)$, attributed to respiratory drugs (aminophylline and theophylline), showed tachycardia (heart rate $>180 / \mathrm{min}$ ) with an increased serum drug level ( $>15 \mathrm{ug} / \mathrm{mL}$ ). Total parenteral nutrition was attributed to 7 cases $(12.3 \%)$ with cholestasis (direct bilirubin $>2.0$ $\mathrm{mg} / \mathrm{dL}$ ) reported in all of the patients. Six cases (10.5\%) were attributed to lipid emulsion (triglycerides $>200 \mathrm{mg} / \mathrm{dL}$ ). Four cases $(7 \%)$ were traced to an antibiotic with all of the cases were 
Table 1. Clinical Symptoms of Adverse Drug Reactions

\begin{tabular}{llcl}
\hline Drug class & \multicolumn{1}{c}{ Drug } & Cases & \multicolumn{1}{c}{ Reported adverse drug reactions } \\
\hline Methylxanthines & Theophylline, Aminophylline & 8 & Tachycardia (1) \\
& & & TDM $\uparrow(7)$ \\
Lipid & SMOFlipid & 6 & TG $\uparrow(6)$ \\
TPN & Aminoacid & 7 & TPN cholestasis (7) \\
& SMOFlipid & & \\
Antimicrobial & Vancomycin & 4 & SCr $\uparrow(2), \operatorname{ARF}(1), \operatorname{TDM} \uparrow(1)$ \\
Antivirals & Ganciclovir & 1 & Rash (1) \\
NSAIDs & Ibuprofen & 4 & ARF (1), PLT $\downarrow$ (1), SCr $\uparrow(1), \mathrm{GI}$ bleeding (1) \\
Vaccination & Synagis & 2 & Desaturation (1), Apnea (1) \\
Sedatives & Phenobarbital & 4 & Desaturation \& TDM $\uparrow(4)$ \\
Electrolytes & Magnesium (maternal) & 12 & Hypermagnesemia (12) \\
& Magnesium (TPN) & 9 & Hypermagnesemia (9) \\
\hline
\end{tabular}

Abbreviations: TDM, therapeutic drug monitor; SMOFlipid, soya oil medium-chain triglycerides olive oil and fish oil-based lipid emulsion; TG, triglyceride; TPN, toral parenteral nutrition; SCr, serum creatinine; NSAIDs, nonsteroidal anti-inflammatory drugs; ARF, acute renal failure; PLT, platelet; GI, gastrointestinal tract.

attributed to the same drug (vancomycin), and increases in serum creatinine ( $>1.5 \mathrm{mg} / \mathrm{dL}$ ), oliguria (urine output $<1.0 \mathrm{~mL} /$ $\mathrm{Kg} / \mathrm{hr}$ ), and serum drug level (through level $>10 \mathrm{ug} / \mathrm{mL}$ ) were reported. Nonsteroidal anti-inflammatory drugs (NSAIDs, ibuprofen), reported in 4 cases ( $7.0 \%)$, were prescribed in all of the cases to treat patent ductus arteriosus where the related sign were oliguria, thrombocytopenia $\left(<60,000 / \mathrm{mm}^{3}\right)$, increased serum creatinine, and gastrointestinal bleeding. Four cases (7.0 \%) of phenobarbital use showed decreased activity, oxygen desaturation and an increased serum drug level ( $>40 \mathrm{ug} / \mathrm{mL}$ ). Two (3.5\%) cases were related to Synagis with oxygen desaturation and apnea, whereas the antiviral agent ganciclovir was related to 1 case (1.8\%) with skin rashes (Table 1).

\section{Results of adverse drug reaction evaluation}

When the adverse drug reaction causality of the 57 cases were tested according to Naranjo's scale, there were 0 definite cases (0\%), 42 probable cases ( $73.7 \%), 13$ possible cases $(22.8 \%)$, and 2 doubtful cases (3.5\%), with the majority being categorized as "probable" cases. Evaluation using the WHO-UMC standard resulted in 1 certain case $(1.8 \%), 12$ probable or likely cases (21.1\%), 41 possible cases (71.9\%), 1 unlikely case (1.8\%), 0 conditional or unclassified cases, and 2 unassessable or unclassifiable cases (3.5\%), with the majority categorized as "possible" cases. According to the Korean algorithm, 2 cases were certain (3.5\%), $30(52.6 \%)$ were probable or likely, $23(40.4 \%)$ were possible, and 2 (3.5\%) were unlikely, with the majority being categorized as "probable or likely." Fifty-five (96.5\%) of the 57
Table 2. Classification of Adverse Drug Reactions by Each Algorithm

\begin{tabular}{|c|c|c|}
\hline $\begin{array}{l}\text { Naranjo's scale } \\
(n=57)\end{array}$ & $\begin{array}{c}\text { WHO-UMC } \\
(n=57)\end{array}$ & $\begin{array}{c}\text { Korean algorithm } \\
(\mathrm{n}=57)\end{array}$ \\
\hline Definite (0) & Certain (1) & Certain (2) \\
\hline Probable (42) & Probable/likely (12) & Probable/likely (30) \\
\hline Possible (13) & Possible (41) & Possible (23) \\
\hline \multirow[t]{3}{*}{ Doubtful (2) } & Unlikely (1) & Unlikely (2) \\
\hline & Conditional/Unclassified (0) & \\
\hline & Unassessable/Unclassifiable (2) & \\
\hline
\end{tabular}

Abbreviations: N, number; WHO-UMC, World Health OrganizationUppsala Monitoring Centre.

reported cases were classified as meaningful i.e., having more than a possible likelihood of causality in all of the 3 tests $^{13)}$ (Table 2).

\section{DISCUSSION}

Adverse drug reactions in neonates related with increased mortality and morbidity ${ }^{14,15)}$. Adverse drug reactions in newborns are related to their immature drug metabolism systems and occur three times more often than in adult cases ${ }^{3)}$. The following points should be considered to understand drug metabolism disadvantages in neonates ${ }^{8}$. First, because drug metabolism can vary widely depending on the postnatal age or gestational age, some drugs that can be dangerous at high serum level (aminophylline, digoxin, aminoglycoside, and anti- 
convulsants) must be administered while monitoring serum drug levels ${ }^{8)}$. In the result of this study, 33 cases of total 57 cases were associated with the increased serum drug level at the therapeutic drug monitoring. Second, because gastrointestinal blood flow and muscle blood flow are impaired until sufficient post birth adjustment, drug absorption from the digestive system and muscles is insufficient and unstable, requiring intravenous administration of necessary medications ${ }^{16)}$. Third, the plasma protein levels, especially albumin, are low, resulting in increased free fractions of drug substances and indicating that a lower blood concentration is sufficient to reach effective concentration levels ${ }^{17}$. Fourth, when drugs that compete with bilirubin at albumin-binding sites are used, the concentration of free bilirubin increases, thereby augmenting the risk of kernicterus. Fifth, the immaturity of the blood-brain barrier results in a high risk of drug-induced central disorders. Sixth, the large amount of extracellular fluid means a larger drug dispersion area than that in adults and a wider dispersion from the blood stream to the interstitial cells ${ }^{16)}$. Seventh, neonates have a low activation of enzymes in the metabolism of drugs and an imbalance caused by the slower development of phase II conjugation system (of glucuronic acid). The majority of drugs are actively excreted from the liver as glucuronic bile acids. Thus, the immaturity of liver functions leads to delayed drug metabolism ${ }^{18)}$. Eighth, although water soluble drugs and their metabolites are excreted by the kidneys, kidney functions vary widely depending on the gestation age as well as post-natal age, requiring large adjustments in the drug administration schedule. In other words, the immaturity of kidney functions results in the delay of drug elimination. Some adverse drug reactions of this study were associated with increased serum creatinine level, oliguria, and delayed elimination of drugs. Ninth, the immaturity of organ drug receptors, as well as the organs themselves, can cause different pharmacological effects. Tenth, there can be side effects specific to the neonatal stage, such as the impact on the developmental process (ciprofloxacin, levofloxacin). Eleventh, the neonatal skin is thin with fewer keratin layers and an extremely high blood flow. The neonatal skin can absorb unexpected substances in unexpected amounts, requiring greater care. Twelfth, neonates can be affected by drugs administered to the mother through the placenta and milk ${ }^{16)}$.

Such vulnerabilities in drug metabolism at the neonatal stage increase the danger of adverse drug reactions; however, there have been few studies examining adverse drug reactions in neonatal intensive care units and has not reported in Korea. Among the 410 patients hospitalized during the study period, 57 cases of adverse drug reactions were reported in 40 patients, representing $9.8 \%$ of the total patients. Of 43,641 individual prescriptions, there were 57 cases of adverse drug reactions, showing a $0.13 \%$ incidence. This finding is similar to 1.2 to 1.8 adverse drug reactions for every 1,000 prescriptions at a level III pediatric hospital ${ }^{19,20)}$, but lower than $30 \%$ of high-risk neonates experiencing adverse drug reactions among neonatal intensive care unit (NICU) patients ${ }^{6,7)}$. This result may be attributed to a lower proportion of cases suspected of adverse drug reactions and was reported as such. The majority of adverse drug reactions were reported by nurses directly in charge of patient care at the time this study was conducted by doctors. Thus, active interest on the part of all medical staff, including nurses is required. According to the reported adverse drug reactions, the largest number of cases was caused by magnesium sulfate administered to the mother ${ }^{21}$, demonstrating the unique characteristics of neonatal drug metabolism reactions. In this study, magnesium sulfate was administrated at $17.6 \pm 29.3$ hours before the delivery time due to the pregnancy induced hypertension, and the administrated dose was $21.1 \pm 23.2 \mathrm{~g}$. Moreover, this finding is distinct from that observed in adult cases, in which skin symptoms are most frequent, and in children, in whom vaccine-related incidents occur most frequently ${ }^{22,23)}$, indicative of the uniqueness of neonatal adverse drug reactions. In the reported cases, suspicion based on the results of serologic tests $(n=50$ cases, $87.8 \%$ ) far outnumbered suspicion based on the clinical symptoms ( $\mathrm{n}=7$ cases, $12.3 \%$ ). This finding was the possible underlying cause in a high proportion ( $\mathrm{n}=55$ of $57,96.5$ $\%$ ) of cases evaluated as meaningful adverse drug reactions by scoring above possible causality in all 3 evaluation tests. Furthermore, the therapeutic drug monitoring was not evaluated in all patients, which was a confusing. Additional efforts must be made to suspect adverse drug reactions based on clinical symptoms and to actively report and examine cases as necessary to reduce the incidence of likely adverse drug reactions. This study demonstrated the unique characteristics of adverse drug reactions in newborns, showing the need to fully consider various problems based on the immaturity of enzyme systembased metabolism, inadequate kidney and liver functions, which result in delayed elimination, and the impact of drugs on jaundice, development and growth. This study had many limitations because it was a retrospective research based on a small 
number of subjects at a single neonatal intensive care unit. There were limited information about the dose-related effect, time-related effect guessing the relationship between the drug administration timing and adverse drug reaction. Additional, prospective study with larger-scale should be undertaken in the future. Although it may be impossible to predict and prevent all adverse drug reactions, it is highly important to conduct accurate monitoring and evaluation towards that goal. Clinicians should monitor prescribing pattern more clinically to identify potential risks in NICU patients in relation to the evolving pattern of medicine use among neonates. More emphasis is warranted in the field of neonatal adverse drug reactions.

\section{ACKNOWLEDGMENT}

This study was partly supported by the Dong-A University Research Fund.

\section{REFERENCES}

1) Du W, Lehr VT, Lieh-Lai M, Koo W, Ward RM, Rieder MJ, et al. An algorithm to detect adverse drug reactions in the neonatal intensive care unit. J Clin Pharmacol 2013;53:87-95.

2) Edwards IR, Aronson JK. Adverse drug reactions: definitions, diagnosis, and management. Lancet 2000;356:1255-9.

3) Impicciatore P, Choonara I, Clarkson A, Provasi D, Pandolfini $\mathrm{C}$, Bonati $\mathrm{M}$. Incidence of adverse drug reactions in paediatric in/out-patients: a systematic review and meta-analysis of prospective studies. Br J Clin Pharmacol 2001;52:77-83.

4) Fabiano V, Mameli C, Zuccotti GV. Adverse drug reactions in newborns, infants and toddlers: pediatric pharmacovigilance between present and future. Expert Opin Drug Saf 2012;11:95105.

5) Kaushal R, Goldmann DA, Keohane CA, Abramson EL, Woolf $\mathrm{S}$, Yoon C, et al. Medication errors in paediatric outpatients. Qual Saf Health Care 2010;19:e30.

6) Aranda JV, Cohen S, Neims AH. Drug utilization in a newborn intensive care unit. J Pediatr 1976;89:315-7.

7) Aranda JV, Portuguez-Malavasi A, Collinge JM, Germanson T, Outerbridge EW. Epidemiology of adverse drug reactions in the newborn. Dev Pharmacol Ther 1982;5:173-84.

8) Johnson PJ. Neonatal pharmacology--pharmacokinetics. Neonatal Netw 2011;30:54-61.

9) Warrier I, Du W, Natarajan G, Salari V, Aranda J. Patterns of drug utilization in a neonatal intensive care unit. J Clin Phar- macol 2006;46:449-55

10) Pandolfini $C$, Bonati M. A literature review on off-label drug use in children. Eur J Pediatr 2005;164:552-8.

11) Naranjo CA, Busto U, Sellers EM, Sandor P, Ruiz I, Roberts EA, et al. A method for estimating the probability of adverse drug reactions. Clin Pharmacol Ther 1981;30:239-45.

12) Hong KS, Park BJ, Sin SG, Yang JS, Lee SM, Kim YN, et al. Development of a Korean algorithm for causality assessment of adverse drug reactions. Korean J Clin Pharmacol Ther 2002; 10:129-42.

13) Rew SY, Koh YI, Shin HY, Park SH, Ryu SH, Kim HN, et al. Reporting and clinical features of adverse drug reactions from a single university hospital. Korean J Asthma Allergy Clin Immunol 2011;31:184-91.

14) Knight M. Adverse drug reactions in neonates. J Clin Pharmacol 1994;34:128-35.

15) Gurwitz JH, Field TS, Harrold LR, Rothschild J, Debellis K, Seger AC, et al. Incidence and preventability of adverse drug events among older persons in the ambulatory setting. JAMA 2003;289:1107-16.

16) Strolin Benedetti M, Baltes EL. Drug metabolism and disposition in children. Fundam Clin Pharmacol 2003;17:281-99.

17) Ehrnebo M, Agurell S, Jalling B, Boréus LO. Age differences in drug binding by plasma proteins: studies on human foetuses, neonates and adults. Eur J Clin Pharmacol 1971;3:189-93.

18) Kearns GL, Abdel-Rahman SM, Alander SW, Blowey DL, Leeder JS, Kauffman RE. Developmental pharmacology--drug disposition, action, and therapy in infants and children. N Engl J Med 2003;349:1157-67.

19) Le J, Nguyen T, Law AV, Hodding J. Adverse drug reactions among children over a 10-year period. Pediatrics 2006;118:55562.

20) Agarwal S, Classen D, Larsen G, Tofil NM, Hayes LW, Sullivan JE, et al. Prevalence of adverse events in pediatric intensive care units in the United States. Pediatr Crit Care Med 2010;11:56878.

21) Lee NY, Cho SJ, Park EA. Influence of antenatal magnesium sulfate exposure on perinatal outcomes in VLBW Infants with maternal preeclampsia. Neonatal Med 2013;20:28-34.

22) Aldea A, García Sánchez-Colomer M, Fernández Quintana E, García Sáiz M. Paediatric adverse drug reactions reported to the Spanish Pharmacovigilance System from 2004 to 2009. Eur J Clin Pharmacol 2012;68:1329-38.

23) Aagaard L, Weber CB, Hansen EH. Adverse drug reactions in the paediatric population in Denmark: a retrospective analysis of reports made to the Danish Medicines Agency from 1998 to 2007. Drug Saf 2010;33:327-39. 